Johanna Lahikainen ja Juuso Ala-Kyyny

\title{
Jäsenistö kertoi näkemyksensä Signumista - verkkojulkaisua kokeillaan vuonna 2022
}

Suomen tieteellinen kirjastoseura (STKS) toteutti toukokesäkuussa kyselyn, jossa kartoitettiin jäsenistön näkemyksiä seuran lehdestä, Signumista, erityisesti sen julkaisemiseen painettuna tai elektronisena. Vastausten perusteella lehteä pidettiin tärkeänä jäsenetuna, mutta sen julkaisumuotoa ei nähty yhtä keskeiseksi asiaksi esimerkiksi jäsenyyden kriteerinä. Jäsenkyselyn vastausten perusteella STKS:n hallitus päätti syksyllä, että elektronista julkaisemista kokeillaan vuonna 2022 siten, että Signum ilmestyy verkkolehtenä (kolme numeroa) ja painettuna lehtenä (yksi numero).

V iime vuosina Suomen tieteellisen kirjastoseuran (sTKs) hallituksessa on keskusteltu Signum-lehden tulevaisuuden vaihtoehdoista. Jäsenistön keskuudessa Signum on nähty korkeatasoisena kirjasto- ja informaatioalan julkaisuna ja tärkeänä jäsenetuna.

Alati nousevat postitus- ja painatuskustannukset rasittavat kuitenkin seuran taloutta, ja tämä kehitys - yhdessä jäsenmäärän kehityksen kanssa - on saanut hallituksen pohtimaan siirtymistä pelkästään verkossa ilmestyvään lehteen. Puheenjohtaja Pälvi Kaiponen ja varapuheenjohtaja Sinikka Luokkanen avasivat tilannetta keväällä $202 \mathrm{I}$ : "Suurin osa työelämän ulkopuolella olevan jäsenen jäsenmaksusta ja yli puolet varsinaisen jäsenen jäsenmaksustakin menee jäsenlehti Signumin kustannuksiin.” (Kaiponen \& Luokkanen 202 I)

Jäsenkysely touko-kesäkuussa Hallitukselle oli selvää, että mahdolliset tulevat päätökset tarvitsevat jäsenistön kannatuksen. Hallitus halusi selvittää kyselyllä lehden merkitystä seuran jäsenille sekä jäsenistön mielipiteitä lehden ilmestymismuodosta. Olisiko jäsenistön toiveissa saada jatkossakin painettu Signum vai saisiko vain sähköisessä muodossa ilmestyvä lehti enemmän kannatusta? Signumia koskeva jäsenkysely toteutettiin 26. 5.-30.6.202 I ja siihen saatiin 79 vastausta. Kiitos kaikille vastanneille!

Kyselystä viestittiin seuran verkkosivuilla, sähköpostilistalla, seuran sosiaalisen median palveluissa (Facebook ja Twitter) sekä päätoimittaja Juuso 
Ala-Kyynyn kirjoittamassa Signumin pääkirjoituksessa numerossa 2/202 I . Kyselyssä tiedusteltiin seuraavia asioita:

1. Kuinka kauan olet ollut STKS:n jäsen?

2. Oletko työelämässä vai työelämän ulkopuolella?

3. Kuinka tärkeänä jäsenetuna pidät Signum-lehteä?

4. Kuinka tärkeänä jäsenetuna pidät kotiin kannettua, painettua Signum-lehteä?

5. Mikäli Signum olisi vain elektroninen lehti, miten se vaikuttaisi haluusi pysyä seuran jäsenenä?

6. Olisitko valmis maksamaan korkeampaa jäsenmaksua, jos saat painetun Signum-lehden?

7. Terveisesi Signumin toimitukselle?

8. Terveisesi STKS:n hallitukselle?

\section{Kyselyn tulokset}

$\mathrm{K}$ yselyn keskeiset tulokset on koottu seuraavalle sivulle. Kyselyyn vastaajilta pyydettiin taustatiedoiksi tieto jäsenyyden pituudesta ja siitä, oliko vastaaja työelämässä vai sen ulkopuolella. Vastaajista 50 henkilöä $(63,3 \%)$ oli ollut seuran jäsenenä yli kymmenen vuotta, I 7 henkilöä (2 I , $5 \%)$ viidestä kymmenen vuotta ja I 2 henkilöä ( I 5,2 \%) alle viisi vuotta. 74 vastaajaa $(93,7 \%)$ oli työelämässä ja viisi $(6,3 \%)$ työelämän ulkopuolella.

Signum-lehteä piti erittäin tärkeänä 26 vastaajaa (32,9\%) ja melko tärkeänä jäsenetuna 40 vastaajaa (50,6\%). Yhteensä siis lehteä piti joko erittäin tai melko tärkeänä 66 vastaajaa $(83,5 \%)$. Yhdeksälle vastaajalle ( I I ,4 \%) lehti ei ollut kovin tärkeä ja kahdelle $(2,5 \%)$ se ei ollut lainkaan tärkeä. Kaksi vastaajista $(2,5 \%)$ valitsi "en osaa sanoa".

Seuraavaksi kysyttiin painetun, kotiin kannettavan Signum-lehden merkityksestä. Erittäin tärkeänä jäsenetuna sitä piti I I vastaajaa $(\mathrm{I} 3,9 \%)$ ja melko tärkeänä I 9 (24, I \%). Ei kovin tärkeäksi sen näki 25 vastaajaa $(3 \mathrm{I}, 6 \%)$ ja ei lainkaan tärkeäksi I 5 (I9\%). Yhdeksän vastaajaa (I I,4\%) valitsi vaihtoehdon "en osaa sanoa".

Kyselyllä haluttiin selvittää myös sitä, vaikuttaisiko Signumin mahdollinen muuttuminen vain sähköiseksi lehdeksi vastaajien haluun jatkaa seuran jäseninä. 49 vastaajaa $(62 \%)$ kertoi, ettei se vaikuttaisi jäsenyyshalukkuuteen. I 2 henkilöä ( I 5,2\%) koki sen vaikuttavan erittäin myönteisesti ja kymmenen melko myönteisesti. Seitsemän jäsentä $(8,9 \%)$ kertoi, että se vaikutti haluun pysyä jäsenenä melko kielteisesti ja yksi ( $1,3 \%)$ erittäin kielteisesti.

Seuran hallitus halusi tietää, olisivatko jäsenet valmiita maksamaan korkeampaa jäsenmaksua painetusta lehdestä. 52 jäsentä $(65,8 \%)$ kertoi, ettei olisi valmiita maksamaan enempää. 23 vastaajaa $(29$, I \%) oli valmis maksamaan kymmenen euroa enemmän ja neljä $(5, \mathrm{I} \%)$ voisi maksaa I 5 euroa enemmän, jotta saisi lehden painettuna. 


\section{Signum-jäsenkyselyn 2021 vastaukset}

Kysely toteutettiin sTKs:n jäsenille 26.5.-30.6.202 I, ja siihen saatiin 79 vastausta.

Kuinka kauan olet ollut

STKS:n jäsen?

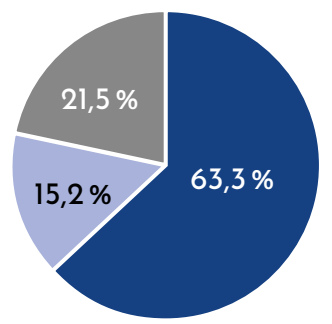

Alle 5 vuotta

5-10 vuotta

yli 10 vuotta

Kuinka tärkeänä jäsenetuna pidät Signum-lehteä?

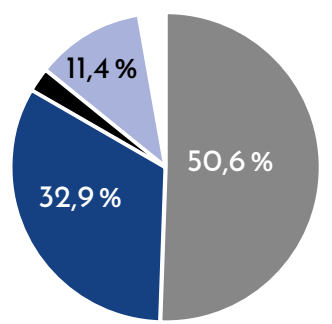

Erittäin tärkeänä

Melko tärkeänä

Ei kovin tärkeänä

Ei lainkaan tärkeänä

En osaa sanoa

Mikäli Signum olisi elektroninen

lehti, miten se vaikuttaisi haluusi

pysyä seuran jäsenenä?

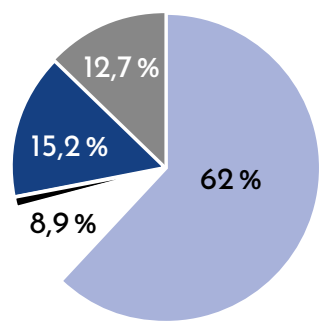

Erittäin myönteisesti

Melko myönteisesti

Melko kielteisesti

Erittäin kielteisesti

Ei vaikuttaisi

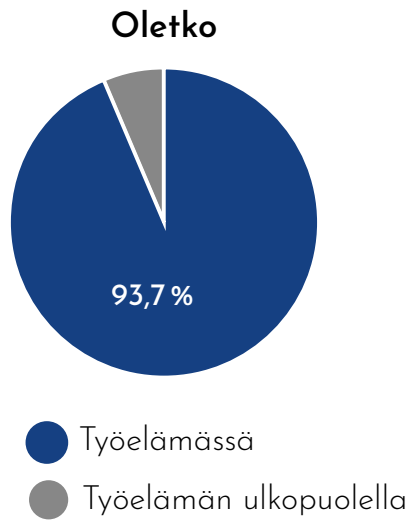

Kuinka tärkeänä jäsenetuna pidät kotiin kannettua, painettua Signum-lehteä?
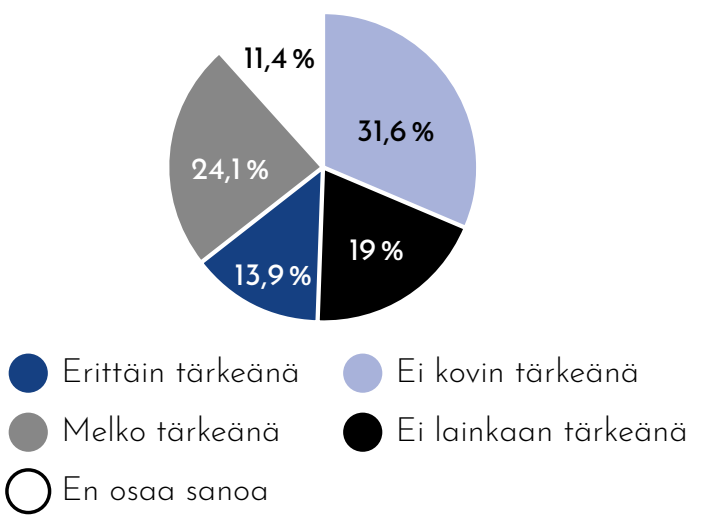

Olisitko valmis maksamaan suurempaa jäsenmaksua, jos saat painetun Signum-lehden?

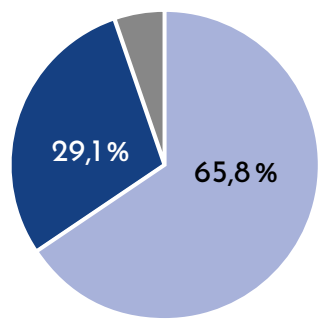

Kyllä, olisin valmis maksamaan $10 €$ enemmän Kyllä, olisin valmis maksamaan $15 €$ enemmän En olisi valmis maksamaan enempää 
Terveisiä Signumille ja STKS:n hallitukselle

Monivalintakysymysten jälkeen oli kaksi kysymystä, joihin sai vastata vapaasti kirjoittamalla. Niissä pyydettiin (I) terveisiä Signumin toimitukselle ja (2) terveisiä sTKs:n hallitukselle.

Näitä avovastauksia tuli ilahduttavan paljon: yhteensä 48 kappaletta, joista toimitukselle 32 ja hallitukselle 16.

Vastaajat antoivat avovastauksissa kehuja ja kiitosta päätoimittajalle ja toimitukselle. Risujakin tuli: toivottiin etteivät kirjoittajat olisi niin usein samoja henkilöitä. Lehden ulkoasua sekä kiitettiin että moitittiin. Osasta se oli vanhanaikainen ja tylsä, osa taas koki sen olevan uudistunut ja tyylikäs.

Lehden tehtävää ja sisältöä pidettiin enimmäkseen tärkeänä. Yksi vastaajista kirjoittaa:

Lehden perustehtävän (= tiedon välittäminen) lisäksi Signum tarjoaa suomalaisille tieteellisten kirjastojen ammattilaisille mahdollisuuden reflektoida työtä̈̈n. Kynnys suomenkielisen tekstin kirjoittamiseen (puoli)tutuille kollegoille on paljon matalampi kuin tekstin sorvaaminen $k v$-journaliin.

Yksi vastaaja kommentoi, että jos seuran jäsenetuna ei enää ole painettua Signumia, tarvitaan jotain muuta etua tilalle.

Verkkoon siirtyminen jakoi mielipiteitä:
Digilehti riittäisi hyvin ja olisi nykyaikaa.

Lehden sähköistäminen sinänsä $O K$, mutta kiva olisi esim. yksi painettu koostenumero tai erikoisnumero vuodessa tms., eli olisi harmi, jos painettu lehti kokonaisuudessaan loppuisi.

Pidän paperista Signumia sähköisen ohella arvokkaana jäsenetuna, ja surisin, jos lehti munttuisi kokonaan elektroniseksi.

\section{Ymmärrän hyvin, jos joudutte luopumaan painetusta.}

En tule lukeneeksi verkkolehtiä, en yksinkertaisesti jaksa. Enkä ole edes iäkäs vielä vaan $40 v$ v. Toivottavasti lebti ilmestyy edelleen painettunakin!

Toimitusta ja hallitusta kannustettiin ideoimaan villisti Signumin tulevaisuutta, hankkimaan sponsoreita, etsimään uusia jäseniä erityisesti opiskelijoista ja satsaamaan näkyvyyteen verkossa ja sosiaalisessa mediassa.

Verkkolehti nähtiin mahdollisuutena uudenlaisiin sisältöihin. Kommenteissa ehdotettiin myös julkaisemista verkossa artikkeli kerrallaan, uutiskirjeen aloittamista ja uudesta lehdestä ilmoittamista sähköpostitse.

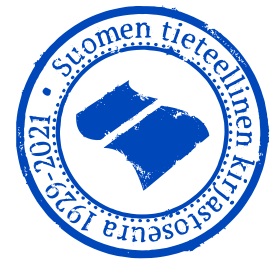




\section{Signum ilmestyy}

\section{verkkolehtenä 2022}

Jäsenkyselyn vastausten perusteella STKs:n hallitus teki syksyllä päätöksen, että Signum ilmestyy vuonna 2022 verkkolehtenä (kolme numeroa) ja painettuna lehtenä (yksi numero). Jäsenkyselyn katsottiin tukevan elektroniseen julkaisemiseen siirtymistä, ja ensi vuosi toteutetaan verkkojulkaisemisen pilotoinnin merkeissä.

"Arvostetun julkaisumme siirtymistä verkkolehdeksi ei tehty kevein mielin, ja hallitus punnitsi tarkoin eri vaihtoehtoja. Katsoimme tärkeäksi, että jäsenet saavat jatkossa välittömästi tiedon, kun uusi Signum on luettavissa verkossa, ja painetun numeron kaavaillaan olevan tuhti lukupaketti vuoden aikana esiin nousseista teemoista. Jäsenkyselyn antia hyödynnetään lehden kehittämisessä uuden päätoimittajan aloittaessa tehtävänsä ensi vuonna", STKs:n hallituksen puheenjohtaja Pälvi Kaiponen sanoo.

Tarkoitus on ensi vuoden aikana kerätä tilastopohjaista dataa verkkolehden käytöstä ja palautetta suoraan käyttäjiltä. Samalla pyritään kehittämään myös tiedotukseen ja viestintään liittyviä keinoja, joilla elektroninen lehti löytää lukijansa.

Verkkolehden numerot ilmestyvät nykyisellä Journal.fi-alustalla osoitteessa https://journal.fi/signum/. Painetun lehden luonteesta hallitus kävi vilkasta keskustelua. Keskeisenä ajatuksena on, että painettu lehti toimisi hieman vuosikirjan tapaan kooten yhteen keskeisiä aiheita ja artikkeleita vuoden ajalta.

Seuran hallitus ja Signumin toimituskunta kiittävät lukijoita palautteesta ja toivovat saavansa sitä jatkossakin. Kehitetään lehteä yhdessä!

\section{Lähde:}

Kaiponen, Pälvi \& Luokkanen, Sinikka, 202 I. Katsaus seuran toimintaan talouden näkökulmasta. Julkaisussa Signum I/202 I, https://doi.org/I0.25033/sig. I07803.

JOHANNA LAHIKAINEN

Helsingin yliopiston kirjasto

johanna.lahikainen@helsinki.fi
JuUso Ala-Kyyny

Helsingin yliopiston kirjasto juuso.ala-kyyny@helsinki.fi

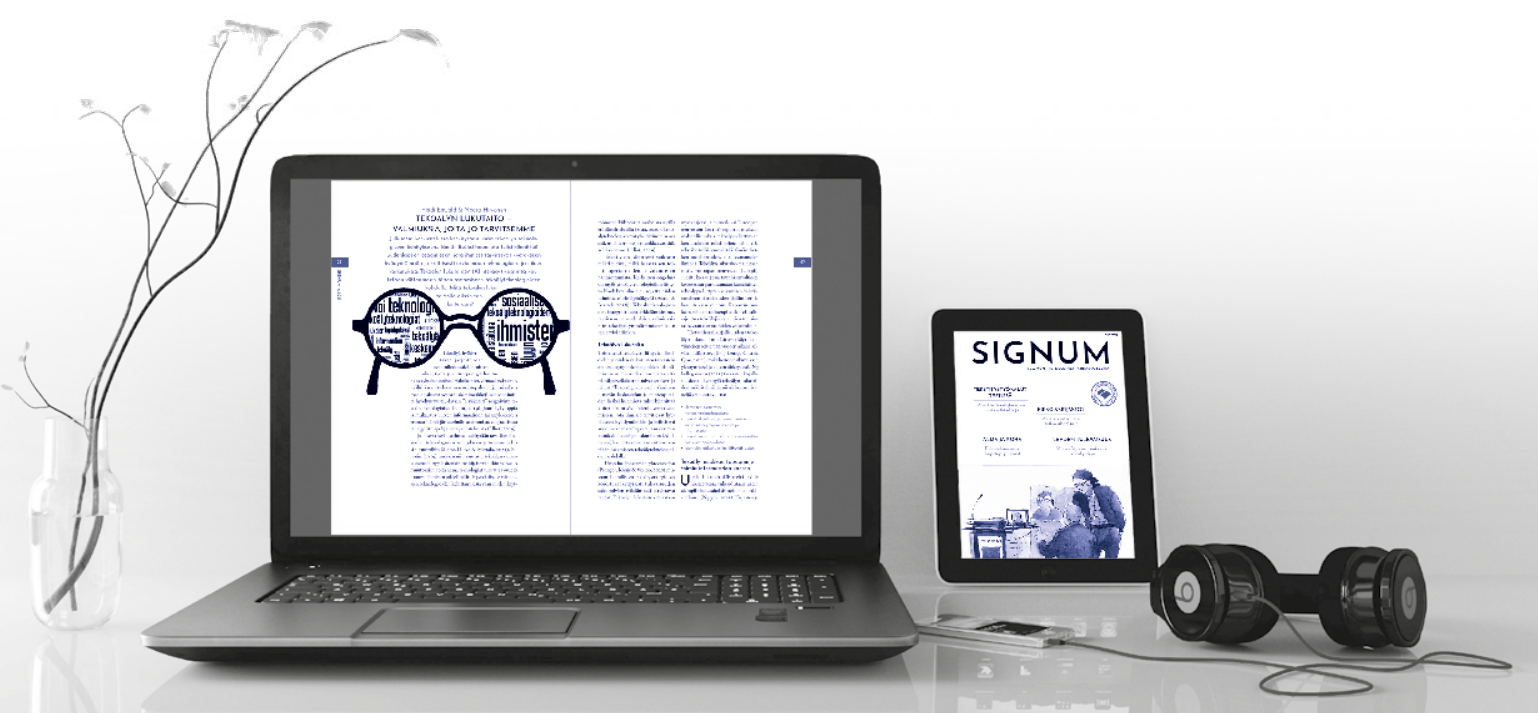

